\title{
Global expression profiling of theophylline response genes in macrophages: evidence of airway anti-inflammatory regulation Pei-Li Yao ${ }^{\dagger 1,2}$, Meng-Feng Tsai ${ }^{\dagger 1,2}$, Yi-Chen Lin1,2, Chien-Hsun Wang2,3, Wei- Yu Liao', Jeremy JW Chen*2,3 and Pan-Chyr Yang*1,2
}

\begin{abstract}
Address: ${ }^{1}$ Department of Internal Medicine, National Taiwan University Hospital, No. 7, Chung-Shan South Rd., Taipei 100, Taiwan, ${ }^{2}$ NTU Center for Genomic Medicine, National Taiwan University College of Medicine, Taipei 100, Taiwan and 3 Institutes of Biomedical Sciences and Molecular Biology, National Chung-Hsing University, No. 250, Kuo-Kuang Rd., Taichung 40227, Taiwan

Email: Pei-Li Yao - dalen@mail.utexas.edu; Meng-Feng Tsai - tsai@microarray.mc.ntu.edu.tw; Yi-Chen Lin - vance@microarray.mc.ntu.edu.tw; Chien-Hsun Wang - topo@cm1.hinet.net; Wei-Yu Liao - daphyu@ha.mc.ntu.edu.tw; Jeremy JW Chen* - jwchen@dragon.nchu.edu.tw; PanChyr Yang* - pcyang@ha.mc.ntu.edu.tw

* Corresponding authors †Equal contributors
\end{abstract}

Published: 08 August 2005

Respiratory Research 2005, 6:89 doi:10.1 186/1465-9921-6-89
Received: 08 April 2005

Accepted: 08 August 2005

This article is available from: http://respiratory-research.com/content/6/1/89

(c) 2005 Yao et al; licensee BioMed Central Ltd.

This is an Open Access article distributed under the terms of the Creative Commons Attribution License (http://creativecommons.org/licenses/by/2.0), which permits unrestricted use, distribution, and reproduction in any medium, provided the original work is properly cited.

\begin{abstract}
Background: Theophylline has been used widely as a bronchodilator for the treatment of bronchial asthma and has been suggested to modulate immune response. While the importance of macrophages in asthma has been reappraised and emphasized, their significance has not been well investigated. We conducted a genome-wide profiling of the gene expressions of macrophages in response to theophylline.
\end{abstract}

Methods: Microarray technology was used to profile the gene expression patterns of macrophages modulated by theophylline. Northern blot and real-time quantitative RT-PCR were also used to validate the microarray data, while Western blot and ELISA were used to measure the levels of IL-I3 and LTC4.

Results: We identified dozens of genes in macrophages that were dose-dependently down- or upregulated by theophylline. These included genes related to inflammation, cytokines, signaling transduction, cell adhesion and motility, cell cycle regulators, and metabolism. We observed that IL-I3, a central mediator of airway inflammation, was dramatically suppressed by theophylline. Realtime quantitative RT-PCR and ELISA analyses also confirmed these results, without respect to PMA-treated THP-I cells or isolated human alveolar macrophages. Theophylline, rolipram, etazolate, db-cAMP and forskolin suppressed both IL- 13 mRNA expression ( 25\%, 2.73\%, 8.12\%, $5.28 \%$, and $18.41 \%$, respectively) and protein secretion ( $<10 \%$ production) in macrophages. These agents also effectively suppressed LTC4 expression.

Conclusion: Our results suggest that the suppression of IL-13 by theophylline may be through CAMP mediation and may decrease LTC4 production. This study supports the role of theophylline as a signal regulator of inflammation, and that down regulation of IL- I 3 by theophylline may have beneficial effects in inflammatory airway diseases. 


\section{Introduction}

Asthma is a highly prevalent health problem worldwide that may cause significant morbidity and mortality $[1,2]$. The mechanisms of airflow obstruction in asthma are various, including broncho-constriction with the contraction of the airway's smooth muscle, increased secretion of mucus, mucosal edema with vascular leakage, and the infiltration of inflammatory cells [3]. The pathogenesis of asthma and its susceptibility involve a complex interplay of various genetic and environmental factors, which may modulate airway inflammation and the remodeling processes that are not only present even in mild asthma but also govern the appearance and severity of airway hyperresponsiveness [4].

The inflammatory cells involved include the infiltration of airway $\mathrm{T}$ cells, $\mathrm{T}$ helper cells, mast cells, basophils, eosinophils, and macrophages [5]. Macrophages are the predominant immune effector in the alveolar spaces and airway, and are believed to play a pivotal role in various pulmonary inflammatory disorders $[6,7]$. Recently, their importance in the pathogenesis of asthma has been reappraised and emphasized [8]. Although their role in asthmatic inflammation is still incompletely understood, it is clear that macrophages may participate in airway inflammation though multiple mechanisms. Furthermore, macrophages have been reported to release lukotriene $\mathrm{B} 4$ (LTB4), lukotriene C4 (LTC4), prostaglandin D2 (PGD2), superoxide anion, and lysosomal enzymes in response to immunoglobulin E (Ig E) $[5,9,10]$. They also produce inflammatory mediators, such as platelet-activating factor, interleukin 1 beta (IL1 $\beta$ ), IL-6, IL-8, and tumor necrosis factor- alpha (TNF- $\alpha$ ) [11-14]. These mediators may play important roles in producing broncho-constriction or causing inflammatory changes.

Theophylline is a weak and non-selective inhibitor of phosphodiesterase (PDE) in airway smooth muscle cells. In high doses, theophylline may lead to an increase in intracellular CAMP and CGMP, and mediate the relaxation of airway smooth muscles and suppress airway inflammation [15]. In chronic obstructive pulmonary disease (COPD) patients, theophylline can reduce the total number and proportion of neutrophils, the production of interleukin-8, and neutrophil chemotatic responses, further suggesting its anti-inflammatory effects $[15,16]$. Several studies have also demonstrated that theophylline has a steroid-sparing effect $[17,18]$. Theophylline inhibits the degranulation and release of mediators, including platelet-activating factor, LTC4, cationic proteins, and superoxide anion, from eosinophils, granulocytes, and alveolar macrophages in vitro $[19,20]$. However, the effects of theophylline on gene expressions in macrophages has not been well studied.
In this study, we analyzed the expression profiles of inflammation-related genes of macrophages in response to theophylline, using a human cDNA microarray $[21,22]$. We also identified differentially expressed genes in macrophages after incubating with theophylline. Our study confirmed the diverse roles of theophylline as an immune modulator, which may be helpful in improving its use in the treatment of airway inflammatory disorders.

\section{Methods \\ Cell lines, alveolar macrophage isolation, and theophylline treatment}

Human monocyte cell line THP-1 (ATCC TIB 202; ATCC, Manassas, VA) was grown with RPMI 1640 media (GIBCO-BRL; Gaithersburg, MD) supplemented with 1.5 $\mathrm{g} / \mathrm{l} \mathrm{Na}_{2} \mathrm{HCO}_{3}, 4.5 \mathrm{~g} / \mathrm{l}$ glucose and 10\% FBS (GIBCO-BRL) and then incubated at $37^{\circ} \mathrm{C}$ with $20 \% \mathrm{O}_{2}$ and $5 \% \mathrm{CO}_{2}$. $3.2 \times 10^{-7} \mathrm{M}$ PMA (SIGMA Chemical Co.; St. Louis, MO) was applied to monocyte cultures. After incubating with PMA for 24 hours, monocytes were differentiated into macrophage-like phenotypes. Macrophages were washed three times with RPMI medium containing $10 \%$ FBS and incubated for another 24 hours to eliminate the effects of PMA.

Alveolar macrophages were obtained by bronchoalveolar lavage (BAL) during routine bronchoscopic examination with written informed consent from three smoker patients with chronic bronchitis. BAL was performed from the right middle lobe or lingula using three to five successive aliquots of $20 \mathrm{ml}$ of $0.9 \%$ sterile $\mathrm{NaCl}$. The BAL fluid was centrifuged at $800 \times \mathrm{g}$ for $10 \mathrm{~min}$ at $4{ }^{\circ} \mathrm{C}$. After two washings, the cells were plated on plastic Petri dishes in serumfree RPMI 1640 media and allowed to adhere for $2 \mathrm{~h}$ at $37^{\circ} \mathrm{C}$. Non-adherent cells were removed by washings with PBS. Adherent cells contained more than 95\% alveolar macrophages $[23,24]$. The $5 \times 10^{4}$ cells were plated on 24 well plates with complete RPMI medium. After incubating for 24 hours, theophylline was added to the alveolar macrophages. The study protocol was approved by the National Taiwan University Hospital's Ethics Committee.

The designated concentration of theophylline $(0,2.5,5$, 10 , and $20 \mu \mathrm{g} / \mathrm{ml}$; SIGMA) was added to macrophages (PMA-treated THP-1 cells). The drug treatments covered a proper range of theophylline concentrations corresponding to the clinical plasma therapeutic levels for asthma patients $[17,25]$. After incubation for 24 hours, the cells were harvested with RNAzol B and followed by microarray experiments.

\section{Human CDNA microarray analysis}

Human EST clones with putative gene names were obtained from the IMAGE consortium libraries through its distributor (Research Genetics, Huntsville, AL). The 
Table I: Oligonucleotides for real-time quantitative RT-PCR

\begin{tabular}{|c|c|c|}
\hline mRNA targets & Oligonucleotides $\left(5^{\prime} \rightarrow 3^{\prime}\right)$ a & Product size (bp) \\
\hline \multirow[t]{2}{*}{ IL-5 } & FI80: ATAGCCAATGAGACTCTGAGGATTC & 89 \\
\hline & R268: AGTGTGCCTATTCCCTGAAAGAT & \\
\hline \multirow[t]{2}{*}{ IL-13 } & FI55: TGAGGAGCTGGTCAACATCA & 76 \\
\hline & R230: CAGGTTGATGCTCCATACCAT & \\
\hline \multirow[t]{2}{*}{ IL-18 } & F2। I: GCTGAACCAGTAGAAGACAATTGC & 94 \\
\hline & R304: CCAGGTTTCATCATCTTCAGCTA & \\
\hline \multirow[t]{2}{*}{$|\mathrm{IL}-| 3 \mathrm{R} \alpha \mid$} & F495: GGAATACCAGTCCCGACACTAACT & 93 \\
\hline & R587: GGCCTTCTCTAAAGATGTTTTCACA & \\
\hline \multirow{2}{*}{ IL-I3R $\alpha 2$} & F44: GGCTATTTGAAGTCGCCATAACC & 78 \\
\hline & RI2I: AGATTTAAAACCTTGATATTGCCTCTCT & \\
\hline \multirow[t]{2}{*}{ TNF- $\alpha$} & F4I4: CTCGAACCCCGAGTGACAA & 64 \\
\hline & R477: AGCTGCCCCTCAGCTTGA & \\
\hline \multirow[t]{2}{*}{ VEGF-a } & FI200: AACACACACTCGCGTTGCAA & 69 \\
\hline & RI268: CGGCTTGTCACATCTGCAAGT & \\
\hline \multirow[t]{2}{*}{ VEGF-c } & FII93: AGATGCCTGGCTCAGGAAGA & 74 \\
\hline & RI266: ATGTCATGGAATCCATCTGTTGAGT & \\
\hline \multirow[t]{2}{*}{ GM-CSF } & FII9: GCCCTGGGAGCATGTGAA & 78 \\
\hline & RI96: TTCATCTCAGCAGCAGTGTCTCTA & \\
\hline \multirow[t]{2}{*}{ TBP } & F852: CACGAACCACGGCACTGATT & 89 \\
\hline & R940: TTTTCTTGCTGCCAGTCTGGAC & \\
\hline
\end{tabular}

a $F$ and $R$ indicate forward and reverse primers, respectively. Numbers indicate the mRNA sequence position.

cDNA microarray with 9,600 PCR-amplified cDNA fragments was prepared by an arraying machine. Five micrograms of mRNAs were labeled with Biotin-16-dUTP during the reverse transcription as described in our previous report [22]. All of the experiments were individually performed in triplicate. The microarray images were scanned, digitized, and analyzed using a flat scanner (PowerLook 3000, UMAX, Taipei, Taiwan) and GenePix 3.0 software (Axon, Union City, CA). The replicates were used to calculate the mean and standard deviation of gene expression and the coefficient of variation $(\mathrm{CV})$ as the measurement of reproducibility. The details of target preparation, hybridization, color development, image analysis, and spot quantification have been described previously $[21,22]$. (see online supplemental data for additional details on the microarray system) (see additional file: 1$)$.

\section{Northern blotting and real-time quantitative RT-PCR}

To confirm the results derived from the microarray, six differentially expressed clones were randomly selected from the cluster analysis and the entire inserts of the clones were individually PCR-amplified to serve as probes for Northern blotting. The amplified cDNA fragments were labeled with digoxigenin-11-dUTP by random primed labeling as our previous report [21]. To correct the quantity of RNA loading, the signals were normalized with the mRNA expression level of GAPDH in the same blot.
Due to the limitations of mRNA extraction from non-proliferated macrophages and low expression levels of some genes, we employed real-time quantitative RT-PCR (RTQRT-PCR) with SYBR Green detection to confirm the results derived from the microarray. There were eight differentially expressed clones randomly selected from the cluster analysis for RTQ-RT-PCR analyses. The TATA box binding protein $(T B P)$ was used as an internal control. The primers were shown in Table 1 and detailed procedures have been described previously [22]. All of the experiments were performed in triplicate.

\section{Western blotting analysis and ELISA}

The details of nuclear extract preparation and Western blot analysis have been described previously [26]. IL-13 was detected using a 1:500 dilution of mouse monoclonal anti-IL-13 primary antibody, a 1:1000 dilution of HRPconjugated anti-mouse IgG secondary antibody (Santa Cruz Biotech, Santa Cruz, CA), and the Western blotting luminol reagent (Santa Cruz Biotech) as detection reagent. $\alpha$-tubulin, used as the control for gel loading, was detected using mouse monoclonal anti- $\alpha$-tubulin primary antibody (Santa Cruz Biotech). In addition, the cultured medium was collected and centrifuged to remove cellular debris, and the supernatants were frozen at $-80^{\circ} \mathrm{C}$ until assayed by ELISA (R\&D System Inc., Minneapolis, MN, USA). IL-13 concentrations were determined by comparison to recombinant standards that run parallel with each 
batch of assays. Each sample was determined in duplicate. The sensitivity of this ELISA was at $<32 \mathrm{pg} / \mathrm{ml}$.

\section{Statistical analysis}

All of the experiments were performed in triplicate and analyzed by ANOVA (Excel, Microsoft; Taipei, Taiwan). A $P$ value $<0.05$ was considered statistically significant. In an attempt to reduce variations arising from experimental results of different microarrays, the intensity values of spots from each microarray were re-scaled using a globalscale method. Detailed procedures have been described previously $[21,22]$. Where appropriate, the data are presented as the mean \pm standard deviation. (see online supplement for additional details on the microarray data analysis) (see additional file: 1).

\section{Results \\ Microarray analysis}

Biotin-labeled probes deriving from mRNAs of macrophages (PMA-treated THP-1 cells) stimulated with different concentrations of theophylline were hybridized to microarrays with 9,600 putative genes to profile the gene expression patterns. The CV was $5.26 \%$ and the Pearson correlation coefficient of overall reproducibility for largescale analyses was 0.98 . The results of microarray analyses indicated that 2,724 out of 9,600 EST clones were identified, according to at least one dosage point, whose expression level is larger than the background $(>3,000$ intensity units).

Among these, 341 genes displayed more than a 2-fold expression change across all five study-included dosages in theophylline treatment. 75 genes were randomly selected and sequenced retrospectively after differential expressions were found, to assure that they indeed represented the true transcript. 45 genes were up-regulated and 30 genes were down-regulated by theophylline in macrophages (PMA-treated THP-1 cells). A full list of genes and data related to treatment with theophylline were posted at our Web site. http://w3.mc.ntu.edu.tw/department/gene chip/supplement.htm. In addition, the gene lists of suppressed and enhanced expression were shown in the online data supplement as Tables 1 and 2 (see additional file: 1$)$.

These selected genes were grouped into eight categories by their putative functions on the basis of literature reports (Figure 1). The categories included: (1) cytoskeleton and motility related genes $(\mathrm{n}=11)$, such as caveolin-1 and actin-related protein $3 ;(2)$ signal transduction related genes $(\mathrm{n}=21)$, such as testis-specific kinase 1 and IL-6 signal transducer, (3) transcription regulators $(\mathrm{n}=9)$, such as transforming growth $\beta$-Induced factor and Down syndrome critical region protein $1 ;(4)$ transport regulators $(\mathrm{n}=7)$, such as CD36 and transcobalamin II; (5) cytokines $(\mathrm{n}=4)$, such as
IL-13 and vascular endothelial growth factor (VEGF)-C; (6) cell cycle regulators $(\mathrm{n}=4)$, such as cyclin-dependent kinase inhibitor $1 C$ and ecotropic viral integration site $2 B$; (7) metabolism related genes $(\mathrm{n}=35)$, such as platelet proteoglycan 1 and eukaryotic translation initiation factor 2, subunit 3; and (8) miscellaneous genes (unknown) $(\mathrm{n}=21)$, such as KIAA0703 gene and KIAA0266. We found that $51 \%$ of affected genes were related to signal transduction or metabolism. Genes with multiple roles were also included in more than one category.

\section{Northern blotting and RTQ-RT-PCR}

To substantiate the results of the microarray studies, Northern blot analysis and RTQ-RT-PCR were performed. Six gene expressions that showed more than a 2 -fold change, including ETIF2S3, IRF7, IL6ST, TAFII55, PRG1 and TESK1, were randomly selected and evaluated. Figure $2 \mathrm{~A}$ shows that the results of Northern blot analyses were consistent with of the microarray studies. GAPDH was used as an internal control. The other eight genes selected from microarray analysis were also confirmed by RTQ-RTPCR, including GMCSF, TNF- $\alpha, I L-13 R \alpha 1, I L-13 R \alpha 2$, IL5, IL-18, VEGF- $a$, and VEGF-c (Figure 2B). The IRF7, TAFII55, PRG1, GMCSF, TNF- $\alpha, I L-13 R \alpha 1, I L-5$, and $I L-18$ genes were suppressed by theophylline, whereas ETIF2S3, IL6ST, TESK1, IL-13 Ro2, VEGF- $a$, and VEGF-c were stimulated.

\section{Theophylline down-regulates IL-13 expression}

Microarray analysis revealed that IL-13 expression was dose-dependently suppressed by theophylline. Figure 3A revealed a collection of cropped microarray images $(3 \times 3$ spots) showing gene expression patterns of $I L-13$ in macrophages (PMA-treated THP-1 cells) treated with theophylline. Northern and Western blot analyses also showed a similar suppression of IL-13 production (Figure $3 \mathrm{~B}$ and $3 \mathrm{C}$ ). The concentration of $10 \mu \mathrm{g} / \mathrm{ml}$ of theophylline approximately corresponds to the clinical plasma therapeutic level.

IL-13 mRNA expression in macrophages (PMA-treated THP-1 cells) with different dosages of theophylline treatment was measured by RTQ-RT-PCR, and results showed a significant suppression compared with the control $(\alpha=$ $0.05, p=0.0079$ ) (Figure 4A). ELISA showed that IL-13 protein secretion was also reduced in a dose-dependent manner $(50.23 \%, 32.43 \%, 24.93 \%$, and $5.33 \%$, respectively, of the level seen in the absence of theophylline) (Figure 4B).

In this study, we also evaluated IL-13 expression in human alveolar macrophages using ELISA. Results showed that IL-13 protein secretion was reduced in alveolar macrophages when treated by $10 \mu \mathrm{g} / \mathrm{ml}$ theophylline. The amounts of IL-13 protein in those without 


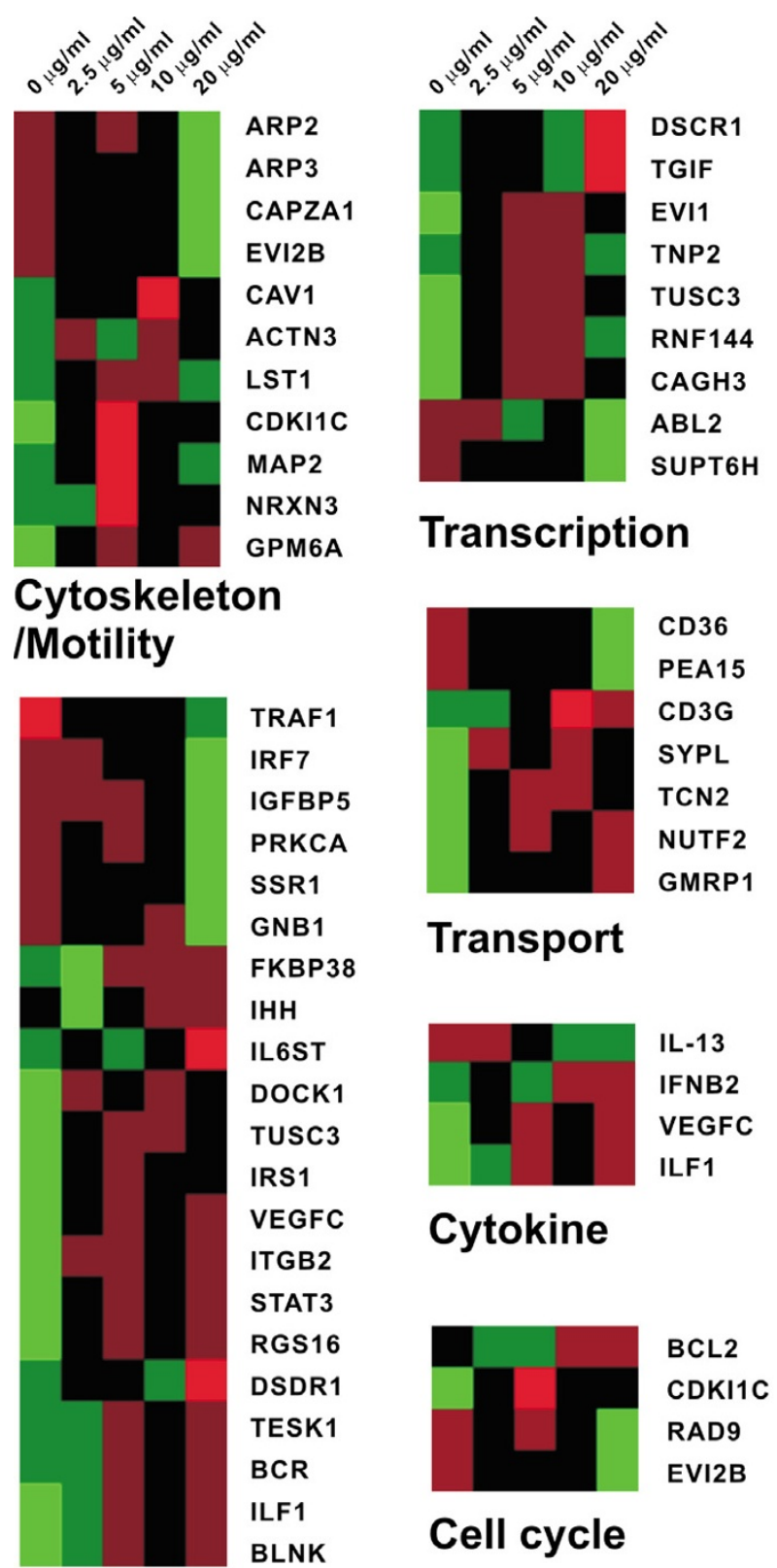

\section{Signal Transduction}

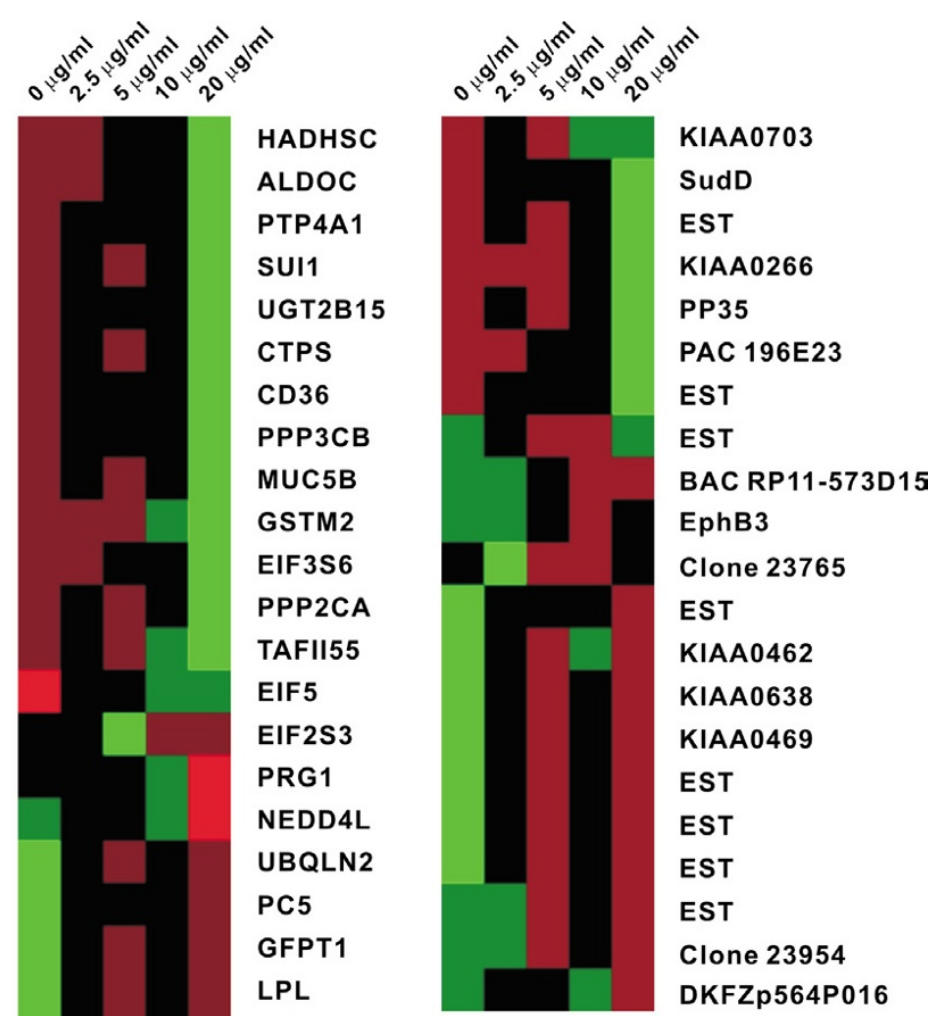

SDS

OSBP

EIF2S3

PLD3

CTSB

TESK1

TPMT

NRXN3

EVI1

HSPA2

FKBP38

$B C R$

EIF3S10

EIF4B

\section{Miscellaneous}

\section{Figure I}

Hierarchical clustering of the gene expression profile in macrophages with or without theophylline. 75 differentially expressed genes dose-dependently down- or up-regulated by theophylline were identified and further grouped into 8 categories. Relative expression levels of these genes are color-coded.

theophilline treatment specimens BAL-A, BAL-B and BAL$\mathrm{C}$ are 224, 283 and $191 \mathrm{pg} / \mathrm{ml}$, respectively. In contrast, there are 86,47 , and $69 \mathrm{pg} / \mathrm{ml}$ of IL-13 in the respective theophylline treatment specimens. In alveolar macrophages from smoker patients with chronic bronchitis, IL13 protein secretion was decreased in a dose-dependent manner with theophylline (Figure 4C).
CAMP-dependent pathways in the down-regulation of IL13 expression

Since theophylline can effectively suppress the production of IL-13 by macrophages, we then examined whether other CAMP-related agents have the same effects. The designated dosages of two phosphodiesterase inhibitors type IV (etazolate and rolipram) and two cAMP-elevating 
(A)
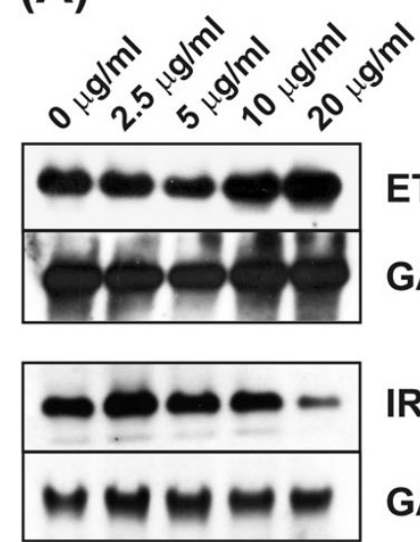

IRF7

GAPDH

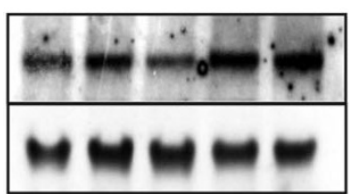

IL6ST

GAPDH

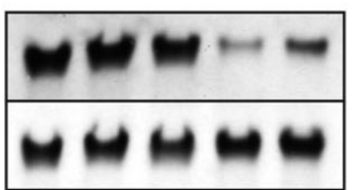

TAFII55

GAPDH

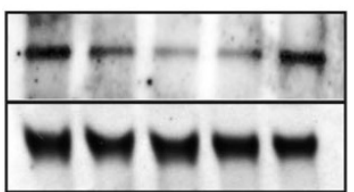

PRG1

GAPDH

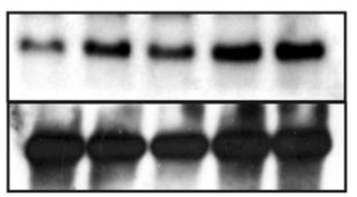

(B)
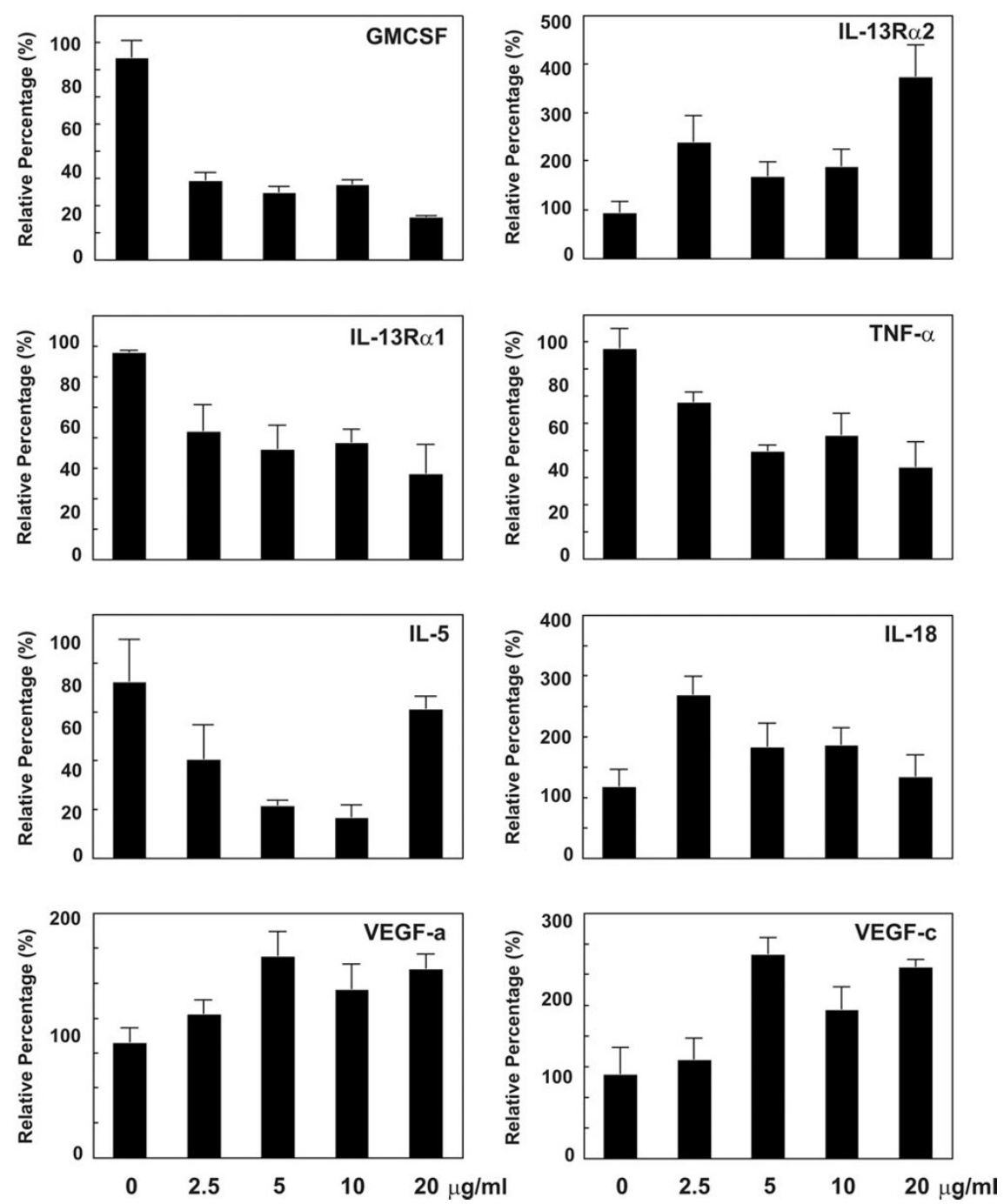

Figure 2

Northern blot and real-time quantitative RT-PCR analyses of differentially expressed genes. (A) Northern blot analysis of six randomly selected genes in macrophages. (B) Real-time quantitative RT-PCR analysis of eight cytokine genes. The relative amount of each cDNA level against to TBP CDNA was measured and defined by an arbitrary unit. $(10 \mu \mathrm{g} / \mathrm{ml}$ of theophylline treatment approximately corresponds to the clinical plasma level.)

agents (forskolin and dibutyryl-cAMP) were added to macrophages (PMA-treated THP-1 cells) separately for 24 hours. Dose-dependent suppression of IL-13 mRNA expression were observed in all four drugs that could increase intracellular cAMP levels $(\alpha=0.05, p=0.0009$ compared to control) (Figure 5A). Similar results were obtained with ELISA $(\alpha=0.05, p=0.0018$ compared to control) (Figure 5B).

\section{Effects on LTC4 expression}

The LTC4 is the downstream target of IL-13. Theophylline and other four cAMP-related drugs (etazolate, rolipram, forskolin, and db-cAMP) could dose-dependently suppress LTC4 secretion by macrophages (Figure 6). As shown in Figure 6A, LTC4 production in macrophages (PMA-treated THP-1 cells) was significantly reduced to $78.34 \%, 34.63 \%, 23.32 \%$, and $13.51 \%$ of the levels seen 
(A)
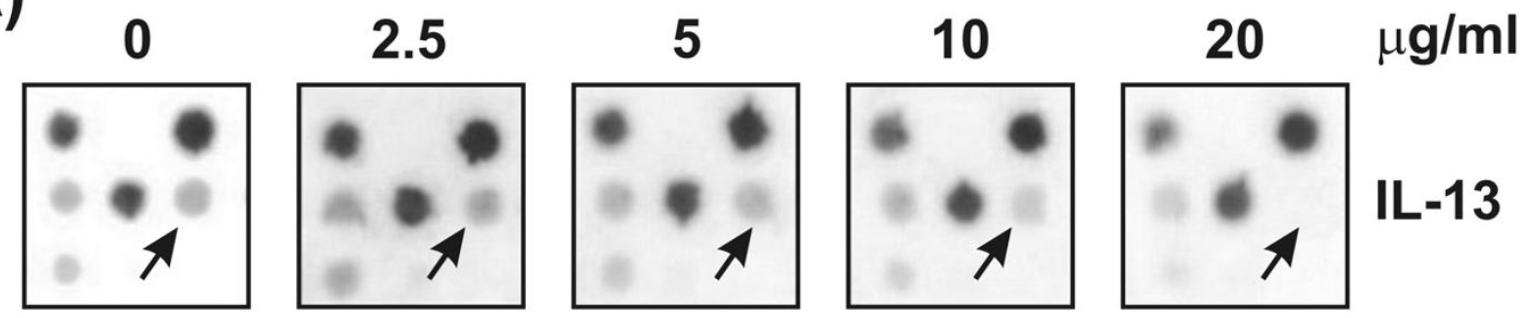

\section{(B)}

\section{(C)}
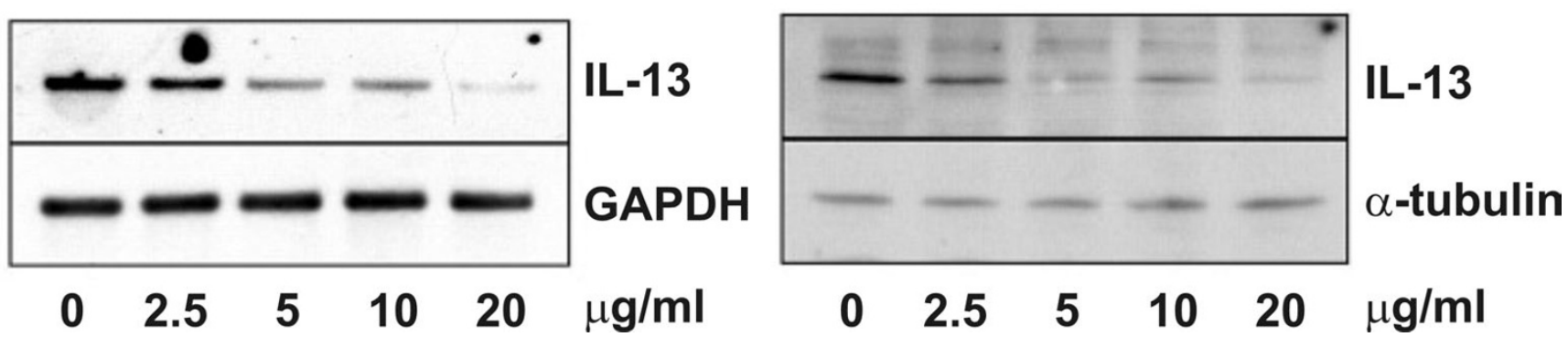

Figure 3

IL-I3 expression in macrophages was suppressed by theophylline in a dose-dependent manner. (A) Close-up view of microarray digital image of IL- 13 expression. (B) Northern blot analysis of IL-I 3 mRNA expression in macrophages. GAPDH was used as an internal control. (C) Western blot analysis revealed that IL-I3 protein level in macrophages was decreased by theophylline. $\alpha$-tubulin was used as the loading control. $10 \mu \mathrm{g} / \mathrm{ml}$ of theophylline treatment approximately corresponds to the clinical plasma level.

in the absence of the drug, respectively, with different dosages of theophylline. Similar results were observed in macrophages (PMA-treated THP-1 cells) treated with other cAMP-related drugs (Figure 6B).

\section{Discussion}

Macrophages are key inflammatory cells that have been documented to play a critical role in various airway disorders [8]. In this study, we analyzed the gene expression profiles of macrophages in response to theophylline. A panel of inflammation related genes was identified, as well as genes associated with angiogenesis, cell adhesion, cell motility, signal transduction, and cell proliferation that are dose-dependently down- or up-regulated by theophylline. Our results revealed that 45 genes were up-regulated and 30 genes were down-regulated by theophylline (supplemental Tables 1 and 2). We also found that theophylline can down-regulate IL-13 expression in macrophages through CAMP mediation, which further leads to decreased LTC4 production. Our results provide positive evidence supporting the role of theophylline as a regulator of inflammation.
In this report, interferon regulatory factor 7 (IRF-7) and CD36 were both suppressed by theophylline in macrophages, especially in high dosages (Figures 1 and 2A, and Supplemental Table 2). IRF-7 has been studied extensively in viral infection [27] and can induce the gene expressions of interferon and cytokine [28]. Interestingly, an overexpression of IRF-7 can trigger monocyte differentiation towards macrophages and induce cell cycle arrest, suggesting a different function for IRF-7 in innate immunity [28]. Furthermore, CD36 is a multi-functional receptor that may play important roles in monocyte/macrophage biology, especially in atherogenic and inflammatory processes [29,30].

Airway inflammation in asthma is regulated by a complex network of cytokines. We found that the expressions of several cytokines were altered within the period of theophylline stimulation (Figure 2B and supplemental Tables 1 and 2). Theophylline can suppress IL-5 and IL-13 production by stimulating peripheral blood nuclear cells (PBMC) [31]. Decreased expression of immuno-regulatory cytokines, including IL-12, IL-18, or interferon gamma, can strengthen the inflammatory process and 

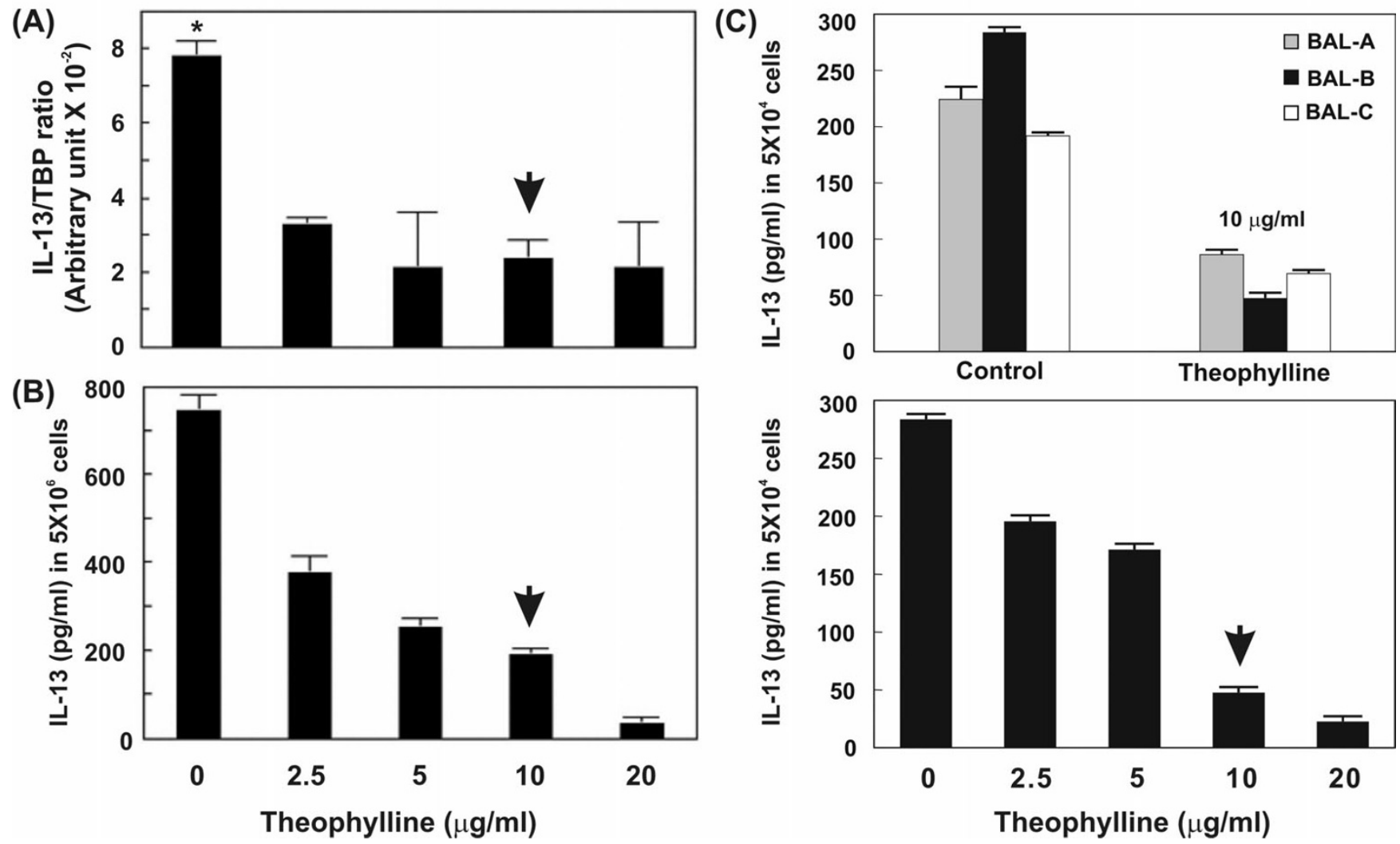

Figure 4

Effects of theophylline on IL- I 3 expression and protein secretion in macrophages. (A) IL- I 3 mRNA level was measured by RTQ-RT-PCR, and significantly decreased after treating with theophylline (down to less than $45 \%$ compared with control. $* \alpha=$ $0.05, p=0.0079)$. (B) IL-I 3 protein secretion, by ELISA analysis, was also reduced in macrophages treated with theophylline. The trend was similar to that for the mRNA (down to less than $55 \%$ compared with control. $* \alpha=0.05, p=0.0075$ ). (C) The IL-I 3 protein secretion in alveolar macrophages isolated from three patients (BAL-A, BAL-B, and BAL-C) with chronic bronchitis was also reduced when treated with $10 \mu \mathrm{g} / \mathrm{ml}$ theophylline $(\alpha=0.05, p=0.043$; upper panel). The BAL-B specimens were treated with difference concentration of theophylline $(0,2.5,5,10,20 \mu \mathrm{g} / \mathrm{ml}$, respectively). IL- I 3 protein secretion was decreased in a dose-dependent manner with theophylline (lower panel). Arrow indicates the concentration of theophylline treatment corresponding to the clinical plasma levels (10 mg/L).

play regulatory roles in asthma by modifying Th2 lymphocyte responses [32]. Using a mouse model of allergic inflammation, it has been shown that GMCSF significantly contributes to the development of allergic airway inflammation, and that dexamethasone can completely inhibit GMCSF release [33]. Our findings reveal similar results in the suppression of $I L-5, I L-18$, and GMCSF in macrophages with theophylline (Figure 2B).

IL-13 is an immuno-regulatory cytokine secreted predominantly by activated Th2 cells [34], and induces dramatically different patterns of gene expression in primary cultures of airway epithelial cells, airway smooth muscle cells, and lung fibroblasts [35]. IL-13 expression is not only in T cells and mast cells but also in both normal alveolar macrophages and those from subjects with pulmonary fibrosis [36]. Some reports demonstrate that IL-13 is overproduced in asthma and have implicated IL13 in pathogenesis of inflammation and airway remodeling responses [37-39]. Although the contribution of macrophage derived IL-13 to disease is still not clear, it has been considered for therapy target because of its ability to stimulate inflammatory and airway hyperreactivity responses. In this study, there is strong evidence supporting that IL13 expression is down-regulated by theophylline in a dose-dependent manner (Figures 3 and 4). We also further confirmed the mRNA expression and protein secretion of IL-13 with RTQ-RT-PCR and ELISA. 
(A)

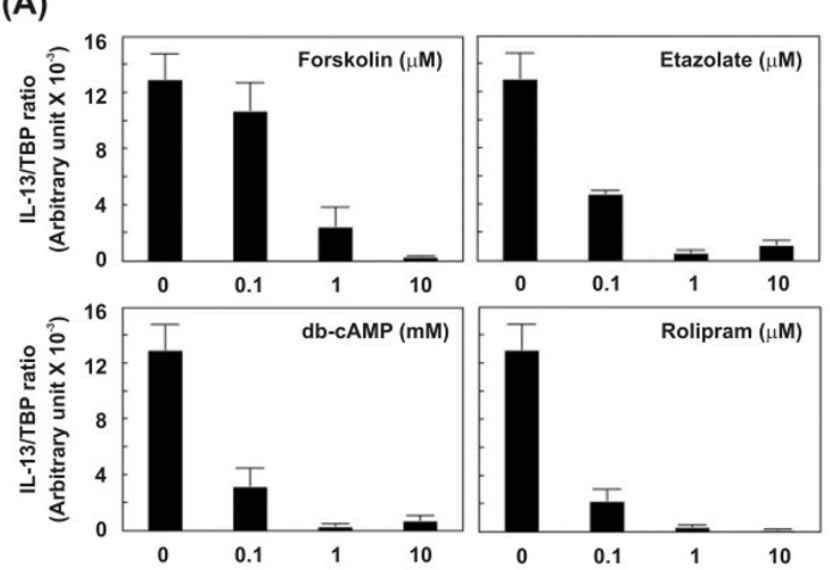

(B)

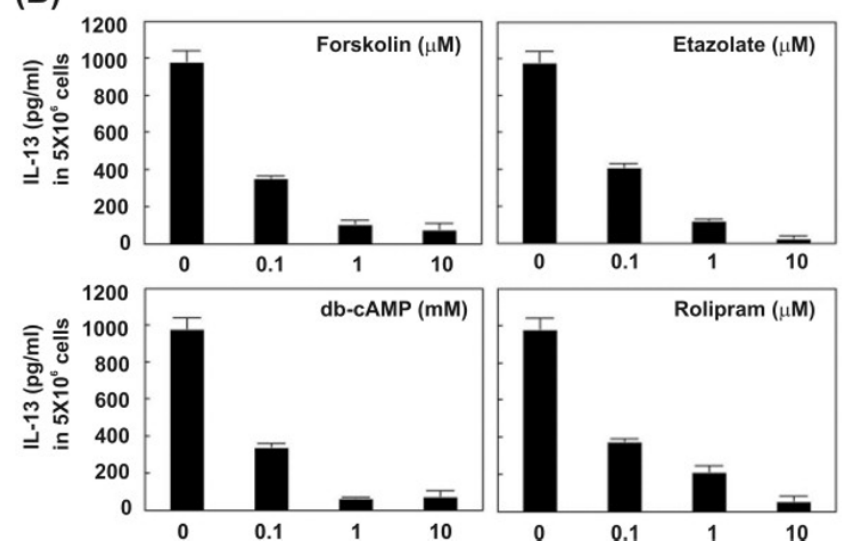

Figure 5

Suppression of IL- I 3 expression in macrophages by PDE type IV inhibitors and cAMP-elevating agents. Two PDE type IV inhibitors, etazolate and rolipram, and two CAMP-elevating agents, forskolin and db-cAMP (dibutyryl-cAMP), were added to macrophage separately for 24 hours. The cells were harvested to extract RNA for RTQ-RT-PCR, and the cultured medium were used to carry out ELISA. (A) RTQ-RT-PCR analysis showed a decrease of IL-I 3 mRNA in a dosedependent manner after treating with four drugs $(\alpha=0.05, p$ $=0.0009)$. (B) The results of ELISA also revealed that IL-I3 protein secretion was reduced after treatment with four drugs $(\alpha=0.05, p=0.0018)$.

In macrophages (PMA-treated THP-1 cells), IL-13R $\alpha 1$ mRNA expression was inhibited by theophylline, whereas IL-13R $\alpha 2$ mRNA expression increased (Figure 2B). IL-13 modifies cell behavior by activating the signal transducer and activator of transcription 6 (STAT-6). Consequently, not only IL-13 concentration but also the density of IL$13 R \alpha 1$ expression may determine the role of IL-13 in the regulation of inflammatory responses in affected tissues. However, not all responses to IL-13 on monocytes and macrophages are dependent on signaling via IL-13R $\alpha 1$
(A)

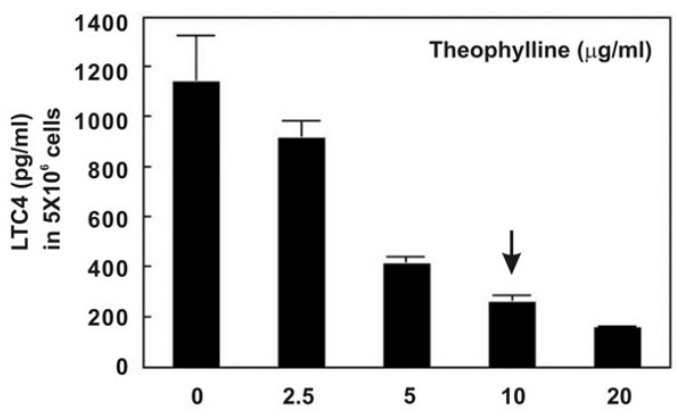

(B)
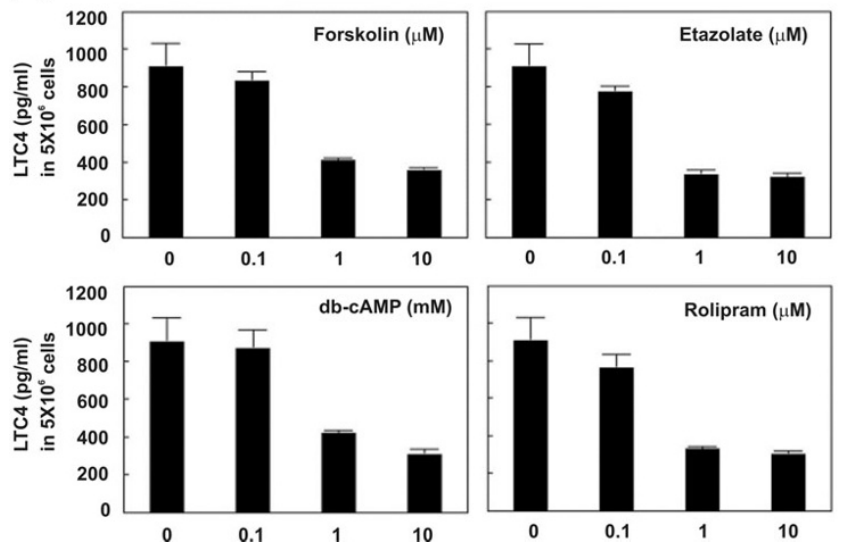

Figure 6

LTC4 secretion by macrophages was suppressed by theophylline and CAMP signaling regulators in a dose-dependent pattern. The cultured medium of macrophages treated with tested drugs was collected to perform ELISA. (A) LTC4 protein secretion was reduced by theophylline stimulation. (B) Etazolate, rolipram, forskolin, and db-cAMP (dibutyryl-cAMP) also suppressed LTC4 protein secretion. Arrow indicates the concentration of theophylline treatment corresponding to the clinical plasma levels $(10 \mathrm{mg} / \mathrm{L})$.

and significant STAT6 activation [40]. Leukotrienes, the products of lipoxygenases, are thought to be important mediators of IL-13-induced asthma phenotype [41]. LTC4 stimulates eotaxin production by IL-13 treated fibroblasts, thereby indirectly inducing eosinophil sequestration [42]. Recently, some studies demonstrated that the regulation of cAMP level by inhibiting PDE activity appears to be involved in the regulation IL-13 release $[43,44]$. The type IV PDE inhibitors have the potential to exert an antiinflammatory effect by inhibiting IL-13 production in lymphocyte and peripheral blood mononuclear cells $[43,44]$.

In this study, we also investigated the influence of cAMP pathway on IL-13 and LTC4 expression in macrophage. We found that etazolate and rolipram, which are PDE type IV inhibitors, can significantly inhibit IL-13 and LTC4 


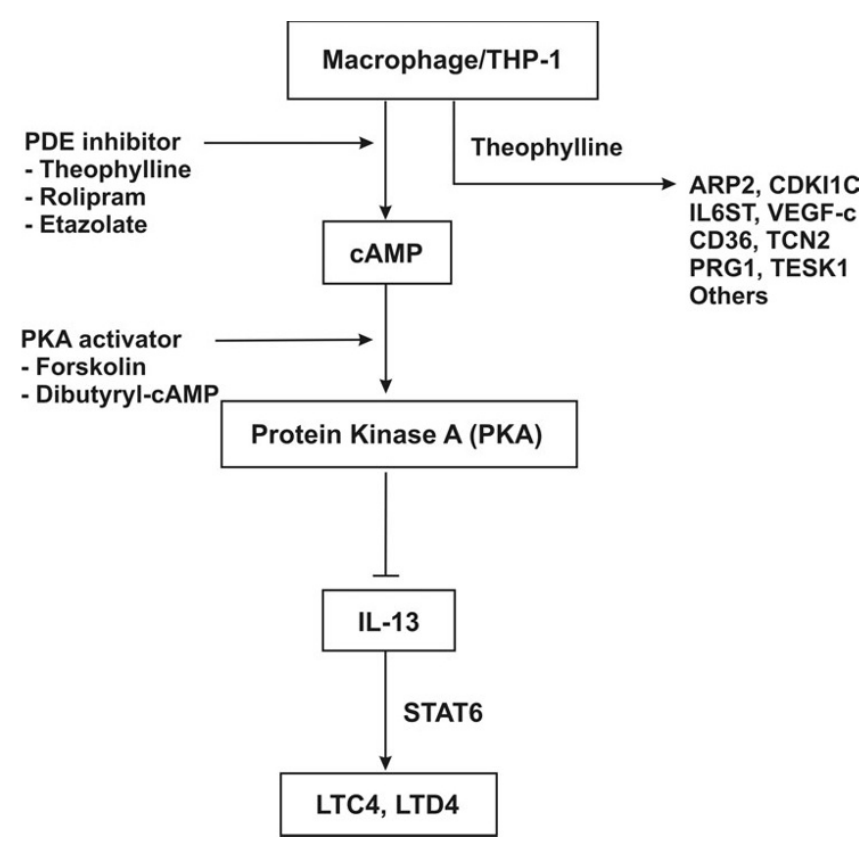

Figure 7

A model for the possible gene regulation in macrophage THP-I stimulated by theophylline. There are many differentially expressed genes involved in the response to theophylline, such as ARP2, IL6ST, VEGF-c, and IL-I3. The suppression of IL- I 3 by theophylline might be through CAMP pathway and further inhibits the expression of LTC4 and LTD4.

production in mRNA and protein level. Similar suppressions are shown in treatment with PKA activator (forskolin and dibutyryl-cAMP). The results indicate that the inhibition of IL-13 and LTC4 might through CAMP and PKA mediation in macrophage. However, the role of PKA in anti-inflammatory effects through cAMP mediation is less established. Although most of the cAMP exerted its downstream effects though the PKA dependent pathway, some actions of cAMP have been reported to be independent of PKA, including the activation of small GTPase Rap1 [45].

In addition, several lines of evidence support that cAMP may act at transcription, post-transcription, or translation levels. For example, cAMP elevating agents can repress NFkappaB dependent transcription by a variety of mechanism [46], and NF-kappaB is also known to be involved in the induction of TNF-alpha, IL-3, and IL-13 in human mast cells [47]. Although the mechanism involved in the regulation of CAMP and IL-13 is still unclear, this study suggests that a possible pathway of the suppressive effects of theophylline on IL-13 expression may be through a cAMP mediated regulation.
As shown in Figure 7, we summarized a model for the possible gene regulation in macrophages (PMA-treated THP1 cells) stimulated by theophylline. Our results suggested that the suppression of IL-13 by theophylline may be through the CAMP pathway and further inhibits the expression of LTC4 and LTD4.

\section{Conclusion}

These data may facilitate the understanding of the diverse anti-inflammatory effects of theophylline, as well as the potential contributing role of macrophages in the pathogenesis of asthma. The importance of theophylline as a signal regulator of inflammation should be re-emphasized. Our results suggest that theophylline could downregulate IL-13 expression in macrophages through cAMP mediation, and further lead to a decrease in LTC4 production, which may have beneficial effects on the therapeutic use of theophylline in pulmonary inflammatory diseases.

\section{Competing interests}

The author(s) declare that they have no competing interests.

\section{Authors' contributions}

PLY performed the RNA isolation, drug treatment and microarray analysis, and drafted the manuscript. MFT performed the alveolar macrophage isolation, culture, drug treatment, ELISA and drafted the manuscript. YCL performed the Northern blotting and real-time RT-PCR experiments. CHW performed the cell culture and realtime RT-PCR experiments. WYL performed the bronchoscopic examination and alveolar macrophage isolation. JJWC and PCY participated in the conception and design of the study as well as proof read the manuscript. All authors read and approved the final manuscript.

\section{Additional material}

\section{Additional File 1}

Supplemental Methods: including microarray system, preparation of biotin-labeled cDNA targets, microarray hybridization and colorimetric detection, and image processing and data analysis. Supplemental Table 1. Differential genes up-regulated by theophylline in macrophage THP-1. Supplemental Table 2. Differential genes down-regulated by theophylline in macrophage THP-1.

Click here for file

[http://www.biomedcentral.com/content/supplementary/14659921-6-89-S1.pdf]

\section{Acknowledgements}

This work was supported by the National Science Council of the Republic of China through the National Research Program for Genomic Medicine grants (NSC 9|-3| | 2-P-002-0|7-Y and NSC 93-3| |2-B-002-026-Y). The 
authors wish to thank the Microarray Core Facility for Genomic Medicine (supported by the National Research Program for Genomic Medicine, NSC) for microarray analysis and technical support.

\section{References}

I. McFadden ER Jr, Warren EL: Observations on asthma mortality. Ann Intern Med 1997, 127:142-147.

2. Myers TR: Pediatric asthma epidemiology: incidence, morbidity, and mortality. Respir Care Clin N Am 2000, 6: I- I4.

3. O'Byrne PM: Leukotrienes in the pathogenesis of asthma. Chest 1997, I I I:27S-34S.

4. Laprise C, Sladek R, Ponton A, Bernier MC, Hudson TJ, Laviolette M: Functional classes of bronchial mucosa genes that are differentially expressed in asthma. BMC Genomics 2004, 5:21.

5. Hamid Q, Tulic' MK, Liu MC, Moqbel R: Inflammatory cells in asthma: mechanisms and implications for therapy. J Allergy Clin Immunol 2003, I I I:S5-SI7.

6. Shepherd MC, Baillie GS, Stirling DI, Houslay MD: Remodelling of the PDE4 cAMP phosphodiesterase isoform profile upon monocyte-macrophage differentiation of human $U 937$ cells. Br J Pharmacol 2004, I 42:339-35I.

7. Heller RA, Schena M, Chai A, Shalon D, Bedilion T, Gilmore J, Woolley DE, Davis RW: Discovery and analysis of inflammatory disease-related genes using cDNA microarrays. Proc Natl Acad Sci USA 1997, 94:2150-2155.

8. Peters-Golden M: The alveolar macrophage: the forgotten cell in asthma. Am J Respir Cell Mol Biol 2004, 3 I:3-7.

9. Fuller RW, Morris PK, Richmond R, Sykes D, Varndell IM, Kemeny DM, Cole PJ, Dollery CT, MacDermot J: Immunoglobulin Edependent stimulation of human alveolar macrophages: significance in type I hypersensitivity. Clin Exp Immunol 1986, 65:416-426.

10. Joseph M, Tonnel AB, Capron A, Voisin C: Enzyme release and superoxide anion production by human alveolar macrophages stimulated with immunoglobulin E. Clin Exp Immunol 1980, 40:416-422.

II. Arnoux B, Duval D, Benveniste J: Release of platelet-activating factor (PAF-acether) from alveolar macrophages by the calcium ionophore A23187 and phagocytosis. Eur J Clin Invest 1980, 10:437-44|.

12. Janson RW, Hance KR, King TE Jr: Human alveolar macrophages produce predominantly the $35-\mathrm{kD}$ pro-forms of interleukinI alpha and interleukin-I beta when stimulated with lipopolysaccharide. Am J Respir Crit Care Med 1995, I 5 1:1613-1620.

13. Lohmann-Matthes ML, Steinmuller C, Franke-Ullmann G: Pulmonary macrophages. Eur Respir J 1994, 7:1678-1689.

14. Wang N, Tabas I, Winchester R, Ravalli S, Rabbani LE, Tall A: Interleukin 8 is induced by cholesterol loading of macrophages and expressed by macrophage foam cells in human atheroma. J Biol Chem 1996, 27 1:8837-8842.

15. Barnes PJ: Theophylline: new perspectives for an old drug. Am J Respir Crit Care Med 2003, I67:813-818.

16. Wang CH, Lin HC, Lin CH, Yu CT, Liu SL, Huang KH, Chung KF, Kuo HP: Effect of theophylline and specific phosphodiesterase IV inhibition on proliferation and apoptosis of progenitor cells in bronchial asthma. Br J Pharmacol 2003, I 38: I |47-I I 55.

I7. Ito K, Lim S, Caramori G, Cosio B, Chung KF, Adcock IM, Barnes PJ: A molecular mechanism of action of theophylline: Induction of histone deacetylase activity to decrease inflammatory gene expression. Proc Natl Acad Sci USA 2002, 99:8921-8926.

18. Tomita K, Chikumi H, Tokuyasu H, Yajima H, Hitsuda Y, Matsumoto $Y$, Sasaki T: Functional assay of NF-kappaB translocation into nuclei by laser scanning cytometry: inhibitory effect by dexamethasone or theophylline. Naunyn Schmiedebergs Arch Pharmacol 1999, 359:249-255.

19. Calhoun WJ, Stevens CA, Lambert SB: Modulation of superoxide production of alveolar macrophages and peripheral blood mononuclear cells by beta-agonists and theophylline. J Lab Clin Med I991, I I 7:5 14-522.

20. Shute JK, Tenor H, Church MK, Holgate ST: Theophylline inhibits the release of eosinophil survival cytokines - is Raf-I the protein kinase A target? Clin Exp Allergy 1998, 28(Suppl 3):47-52.
21. Yu SL, Chen HW, Yang PC, Peck K, Tsai MH, Chen J], Lin FY: Differential gene expression in gram-negative and gram-positive sepsis. Am J Respir Crit Care Med 2004, I 69: I I 35-I I 43.

22. Chen HW, Yu SL, Chen J], Li HN, Lin YC, Yao PL, Chou HY, Chien $C T$, Chen WJ, Lee YT, Yang PC: Anti-invasive gene expression profile of curcumin in lung adenocarcinoma based on a high throughput microarray analysis. Mol Pharmacol 2004, 65:99-I I0.

23. Hancock A, Armstrong L, Gama R, Millar A: Production of interleukin I 3 by alveolar macrophages from normal and fibrotic lung. Am J Respir Cell Mol Biol I998, I 8:60-65.

24. Carre PC, Mortenson RL, King TE Jr, Noble PW, Sable CL, Riches DW: Increased expression of the interleukin- 8 gene by alveolar macrophages in idiopathic pulmonary fibrosis. A potential mechanism for the recruitment and activation of neutrophils in lung fibrosis. J Clin Invest 1991, 88: I802-I8I0.

25. Ohta K, Fukuchi Y, Grouse L, Mizutani R, Rabe KF, Rennard SI, Zhong NS: A prospective clinical study of theophylline safety in 3810 elderly with asthma or COPD. Respir Med 2004, 98: I 01 6-I024.

26. Chen Jj, Yao PL, Yuan A, Hong TM, Shun CT, Kuo ML, Lee YC, Yang PC: Up-regulation of tumor interleukin-8 expression by infiltrating macrophages: its correlation with tumor angiogenesis and patient survival in non-small cell lung cancer. Clin Cancer Res 2003, 9:729-737.

27. Hiscott J, Grandvaux N, Sharma S, Tenoever BR, Servant MJ, Lin R: Convergence of the NF-kappaB and interferon signaling pathways in the regulation of antiviral defense and apoptosis. Ann N Y Acad Sci 2003, I 0 I 0:237-248.

28. Lu R, Pitha PM: Monocyte differentiation to macrophage requires interferon regulatory factor 7. J Biol Chem 200I, 276:4549I-45496.

29. Huh HY, Pearce SF, Yesner LM, Schindler JL, Silverstein RL: Regulated expression of CD36 during monocyte-to-macrophage differentiation: potential role of CD36 in foam cell formation. Blood 1996, 87:2020-2028.

30. Yesner LM, Huh HY, Pearce SF, Silverstein RL: Regulation of monocyte CD36 and thrombospondin-I expression by soluble mediators. Arterioscler Thromb Vasc Biol 1996, 16:1019-1025.

31. Kimura M, Okafuji I, Yoshida T: Theophylline suppresses IL-5 and IL-I 3 production, and lymphocyte proliferation upon stimulation with house dust mite in asthmatic children. Int Arch Allergy Immunol 2003, I 3 I: 189-194.

32. McKay A, Komai-Koma M, MacLeod KJ, Campbell CC, Kitson SM, Chaudhuri R, Thomson L, McSharry C, Liew FY, Thomson NC: Interleukin- 8 levels in induced sputum are reduced in asthmatic and normal smokers. Clin Exp Allergy 2004, 34:904-910.

33. Patel HJ, Belvisi MG, Bishop-Bailey D, Yacoub MH, Mitchell JA: Activation of peroxisome proliferator-activated receptors in human airway smooth muscle cells has a superior antiinflammatory profile to corticosteroids: relevance for chronic obstructive pulmonary disease therapy. I Immunol 2003, I 70:2663-2669.

34. Hershey GK: IL-I 3 receptors and signaling pathways: an evolving web. J Allergy Clin Immunol 2003, I I I:677-690. quiz 69I

35. Lee JH, Kaminski N, Dolganov G, Grunig G, Koth L, Solomon C, Erle DJ, Sheppard D: Interleukin- 13 induces dramatically different transcriptional programs in three human airway cell types. Am J Respir Cell Mol Biol 200I, 25:474-485.

36. Hancock A, Armstrong L, Gama R, Millar A: Production of interleukin I 3 by alveolar macrophages from normal and fibrotic lung. Am J Respir Cell Mol Biol I998, I 8:60-65.

37. Wills-Karp M, Luyimbazi J, Xu X, Schofield B, Neben TY, Karp CL, Donaldson DD: Interleukin-13: central mediator of allergic asthma. Science 1998, 282:2258-226I.

38. Kotsimbos TC, Ernst P, Hamid QA: Interleukin-13 and interleukin-4 are coexpressed in atopic asthma. Proc Assoc Am Physicians 1996, 108:368-373.

39. Zhu Z, Ma B, Zheng T, Homer RJ, Lee CG, Charo IF, Noble P, Elias JA: IL-I3-induced chemokine responses in the lung: role of CCR2 in the pathogenesis of IL-13-induced inflammation and remodeling. J Immunol 2002, I 68:2953-2962.

40. Hart PH, Bonder CS, Balogh J, Dickensheets HL, Vazquez N, Davies KV, Finlay-Jones J], Donnelly RP: Diminished responses to IL-I3 by human monocytes differentiated in vitro: role of the ILI 3Ralphal chain and STAT6. Eur J Immunol 1999, 29:2087-2097.

4I. Grunig G: IL- I 3 and adenosine: partners in a molecular dance? J Clin Invest 2003, I I 2:329-33 I. 
42. Chibana K, Ishii $Y$, Asakura T, Fukuda T: Up-regulation of cysteinyl leukotriene I receptor by IL- 13 enables human lung fibroblasts to respond to leukotriene $\mathrm{C} 4$ and produce eotaxin. J Immunol 2003, I 70:4290-4295.

43. Yoshida N, Shimizu Y, Kitaichi K, Hiramatsu K, Takeuchi M, Ito $Y$, Kume H, Yamaki K, Suzuki R, Shibata E, Hasegawa T, Takagi K: Differential effect of phosphodiesterase inhibitors on IL-I3 release from peripheral blood mononuclear cells. Clin Exp Immunol 200I, I 26:384-389.

44. Essayan DM, Kagey-Sobotka A, Lichtenstein LM, Huang SK: Regulation of interleukin- 13 by type 4 cyclic nucleotide phosphodiesterase (PDE) inhibitors in allergen-specific human $T$ lymphocyte clones. Biochem Pharmacol 1997, 53:1055-1060.

45. de Rooij J, Zwartkruis FJ, Verheijen MH, Cool RH, Nijman SM, Wittinghofer A, Bos JL: Epac is a Rap I guanine-nucleotideexchange factor directly activated by cyclic AMP. Nature 1998, 396:474-477.

46. Ye RD: Beta-Adrenergic agonists regulate NF-kappaB activation through multiple mechanisms. Am J Physiol Lung Cell Mol Physiol 2000, 279:L6I5-L6I7.

47. Lorentz A, Klopp I, Gebhardt T, Manns MP, Bischoff SC: Role of activator protein I, nuclear factor-kappaB, and nuclear factor of activated $\mathbf{T}$ cells in IgE receptor-mediated cytokine expression in mature human mast cells. J Allergy Clin Immunol 2003, I I I:1062-1068.

Publish with Bio Med Central and every scientist can read your work free of charge

"BioMed Central will be the most significant development for disseminating the results of biomedical research in our lifetime. "

Sir Paul Nurse, Cancer Research UK

Your research papers will be:

- available free of charge to the entire biomedical community

- peer reviewed and published immediately upon acceptance

- cited in PubMed and archived on PubMed Central

- yours - you keep the copyright

Submit your manuscript here:

http://www.biomedcentral.com/info/publishing_adv.asp
BiolMedcentral 